\title{
ANALISIS PENGENDALIAN PERSEDIAAN BAHAN BAKU PEMBUATAN KAPAL FIBER PADA CV. HADI MULYONO AIMAS MENGGUNAKAN METODE ECONOMIC ORDER QUANTITY
}

\author{
Khaist Agung Indriyanto ${ }^{1)}$, Tamrin Tajjudin ${ }^{2)}$ Irman Amri $^{3)}$ \\ 1) Mahasiswa Program Studi Teknik Industri Universitas Muhammadiyah Sorong \\ 23)) Dosen Program Studi Teknik Industri Universitas Muhammadiyah Sorong
}

\begin{abstract}
Abstrak
Pada perusahaan yang bergerak dibidang perdagangan yang menghasilkan barang jadi, proses produksi merupakan kegiatan inti dari perusahaan tersebut. Produksi bisa berjalan dengan lancar apabila bahan baku yang merupakan input dari proses produksi tersedia sesuai dengan kebutuhan. Tujuan dari penelitian ini adalah agar dapat merencanakan (planning),mengendalikan (controlling), mengetahui jumlah, frekuensi, total biaya dan juga titik pemesanan kembali bahan baku. Penelitian ini dilakukan pada CV. Hadi Mulyono Aimas dengan menggunakan metode interview dan pengambilan data dari perusahaan(dokumentasi) sesuai dengan data yang dibutuhkan. Kemudian data dianalisis dengan Metode EOQ dan dengan rumus-rumus yang telah ditentukan. Dari hasil pengolahan/analisis data yang didapat bahwa peramalan pada kedua jenis bahan baku yaitu pada peramlan constant dengan nilai SDT pada masing-masing bahan baku 21,88(fiber cair) dan 10,14(serat fiber). Total biaya keseluruhan pada masing-masing bahn baku yaitu Rp. 40.441.576.745,48(fiber cair dan Rp. 6.816.965.490,-(serat fiber). Untuk reorder pointnya yaitu $725 \mathrm{~kg}$ (fiber cair) dan $365 \mathrm{~kg}$ (serat fiber). Ketersediaan bahan baku utama tersebut sangat berpengaruh pada pembuatan kapal fiber pada perusahaan tersebut, jadi perencanaan dan pengendalian persediaan bahan baku pada perusahaan tersebut khususnya dan pada perusahaan lainyya pada umumnya juga sangat penting.
\end{abstract}

\section{Kata Kunci : Bahan baku, Pengendalian Persediaan, EOQ}

\section{PENDAHUL}

\section{Pendahuluan \\ $1 \quad$ Latar Belakang}

Sorong merupakan kota yang menjadi pintu gerbang Pulau Papua. Sebagai wilayah pintu gerbang, menurut administrator Pelabuhan Sorong, untuk kawasan Sorong dan sekitarnya, transportasi laut sangat memegang peranan yang besar untuk memindahkan atau memobilisasi barang dari satu pulau ke pulau yang lainnya maupun untuk memperlancar arus pergerakan atau mobilitas penduduk.

CV. Hadi Mulyono merupakan perusahaan yang bergerak dibidang industry galangan kapal, yang kegiatan utamanya adalah memproduksi kapal fiber. Perusahaan harus bisa mengelola persediaan dengan baik agar dapat memiliki persediaan yang seoptimal mungkin demi kelancaran operasi perusahaan dalam jumlah, waktu, mutu yang tepat serta dengan biaya yang serendah rendahnya.

\section{Rumusan Masalah}

Berdasarkan latar belakang tersebut diatas, maka dapat dirumuskan masalah sebagai berikut :

1. Berapa jumlah kebutuhan bahan baku Fiber Cair dan Serat Fiber dalam 5 tahun?

2. Berapa kali frekuensi dalam satu periode pembelian bahan baku dilakukan, bila perusahaan CV. HADI MULYONO AIMAS menetapkan metode Economic Order Quantity (EOQ)?

3. Berapa total biaya persediaan bahan baku bila perusahaan menetapkan kebijakan Economic Order Quantity (EOQ)? 
4. Berapa batas atau titik pemesanan bahan baku yang dibutuhkan oleh CV. HADI MULYNO AIMAS selama masa tenggang (reorder point)?

\section{Tujuan Penelitian}

Tujuan kerja praktek yang dilakukan oleh penulis antara lain sebagai berikut:

1. Mengetahui jumlah kebutuhan bahan baku Fiber Cair dan Serat Fiber dalam 5 tahun.

2. Mengetahui frekuensi pembelian bahan baku dan jumlah kebutuhan bahan baku yang optimal pada CV. HADI MULYONO.

3. Mengetahui total biaya persediaan $\mathrm{CV}$. HADI MULYONO.

4. Mengetahui titik pemesanan kembali (reorder point) bahan baku pada CVS HADI MULYONO selama masa tenggang.

\section{Batasan Masalah.}

Pada penelitian ini kami membatasi masalah dengan melakukan penelitian khususnya pada bagian pengadaan bahan baku pembuatan kapal fiber pada CV. Hadi Mulyono Aimas Sorong, yaitu Cairan Fiber dan Kain Fiber atau serat fiber.

\section{METODE PENELITIAN}

\section{Jenis Penelitian}

Penelitian ini merupakan jenis penelitian kasus adalah penelitian yang dilakukan secara intensif, terinci dan mendalam terhadap objek suatu organisme, lembaga atau gejala - gejala tertentu yang diteliti.

\section{Variabel Penelitian}

1. Pemakaian bahan baku yang sesungguhnya, dihitung dalam satuan $\mathrm{kg}$

2. Peramalan persediaan bahan baku, dihitung dalam satuan $\mathrm{kg}$

3. Persediaan bahan baku, dihitung dalam satuan $\mathrm{kg}$

4. EOQ (Economic Order Quantity) :
a. Biaya penyimpanan
b. Biaya pemesanan
c. Titik pemesanan kembali (reorder point)
d. Persediaan pengaman (safety stock)

\section{Metode Pengumpulan Data}

1. Metode Interview/Wawancara

2. Dokumentasi

\section{Metode Analisis Data}

3.4.1 Analisis Kebutuhan Bahan Baku

$\hat{Y}=a+b X$

Dimana :

$\hat{\mathrm{Y}}=$ Peramalan kebutuhan bahan baku

$\mathrm{a}=$ Konstanta

$\mathrm{b}=$ Bilangan waktu untuk satuan waktu

$\mathrm{X}=$ Satuan waktu

3.4.2 Analisis pembelian bahan baku

a. $\mathrm{EOQ}=\sqrt{\frac{2 S D}{H}}$

Dimana :

$\mathrm{EOQ}=$ jumlah pembelian optimal yang ekonomi

$\mathrm{S}$ = biaya pemesanan

$\mathrm{D}=$ Penggunaan $/$ permintaan yang diperkirakan per periode waktu

$\mathrm{H}$ = Biaya penyimpanan per unit per tahun.

Biaya penyimpanan $=10 \% \mathrm{x}$ harga beli per unit bahan baku.

b. Frekuensi pemesanan (I)

$$
\mathrm{I}=\frac{R}{E O Q}
$$

Dimana :

I = frekuensi pemesanan

$\mathrm{R}=$ jumlah bahan baku yang dibutuhkan

$\mathrm{EOQ}=$ jumlah pembelian optimal yang ekonomis

\subsubsection{Analisis total biaya persediaan bahan baku}

Analisis ini untuk mengetahui

berapa total persediaan yang terdiri dari biaya pembelian bahan baku, biaya penyimpanan dan biaya pemesanan.

Adapun rumusnya adalah :

Total biaya persediaan bahan baku = biaya pembelian bahan baku + biaya pemesanan + biaya penyimpanan

$$
\mathrm{TIC}=\sqrt{2 \cdot D S H}
$$

Dimana :

$\operatorname{TIC}(\mathrm{Q})=$ total biaya persediaan per tahun

$\mathrm{D}=$ jumlah kebutuhan barang dalam unit $(\mathrm{kg})$

$\mathrm{H}=$ biaya penyimpanan (unit per periode)

$\mathrm{S}$ = biaya pemesanan setiap kali pesanan

3.4.4 Analisis Reorder Point 
ISSN 1979-7540

Reorder point $=$ penggunaan selama lead time + safety stock

Penggunaan selama lead time $=$ lead time $\mathrm{x}$ pengunaan bahan baku

Safety Stock $=$ jumlah standar deviasi dari tingkat kebutuhan x 1,65

Rumus standar deviasi :

Dimana :

$$
\mathrm{SD}=\sqrt{\frac{\sum(X-Y)^{2}}{n}}
$$

$\mathrm{SD}=$ Standar deviasi

$\mathrm{X}=$ pemakaian sesungguhnya

$\mathrm{Y}=$ peramalan / perkiraan pemakaian

$\mathrm{n}=$ jumlah (banyaknya data)

\subsubsection{Uji t}

Keterangan :

$$
\mathrm{t}=\frac{M d}{\sqrt{\frac{\sum x d}{N(N-1)}}}
$$

$\mathrm{t} \quad=$ Tingkat perbedaan hasil perhitungan

Md = Rata - rata dari perbedaan pre test dengan post test

$\mathrm{xd}=$ Deviasi masing - masing subjek $(\mathrm{d}-$ $\mathrm{Md})$

\section{PENGUMPULAN DAN PENGOLAHAN DATA}

1. PENGUMPULAN DATA

Adapun data-data yang dikumpulkan sebagai berikut :

1. Data kebutuhan bahan baku fiber cair dan serat fiber

Tabel 4.1 Data kebutuhan bahan baku fiber cair dan serat fiber

\begin{tabular}{lcc}
\hline \multicolumn{1}{c}{ Bulan } & $\begin{array}{c}\text { Serat fiber } \\
(\mathrm{kg})\end{array}$ & $\begin{array}{c}\text { Fiber cair } \\
(\mathrm{kg})\end{array}$ \\
\hline Des'06-feb'07 & 347.00 & 690.00 \\
\hline Mart-mei & 341.00 & 662.00 \\
\hline Jun-augst & 350.00 & 655.00 \\
\hline Sep-nov & 337.00 & 644.00 \\
\hline Des'07-feb'08 & 345.00 & 698.00 \\
\hline Mart-mei & 316.00 & 632.00 \\
\hline Jun-augst & 340.00 & 655.00 \\
\hline Sep-nov & 355.00 & 705.00 \\
\hline Des'08-feb'09 & 343.00 & 691.00 \\
\hline Mart-mei & 358.00 & 693.00 \\
\hline Jun-augst & 346.00 & 671.00 \\
\hline Sep-nov & 337.00 & 682.00 \\
\hline Des'09-feb'10 & 334.00 & 668.00 \\
\hline
\end{tabular}

\begin{tabular}{lll}
\hline Mart-mei & 336.00 & 687.00 \\
\hline Jun-augst & 348.00 & 640.00 \\
\hline Sep-nov & 324.00 & 710.00 \\
\hline Des'10-feb'11 & 335.00 & 681.00 \\
\hline Mart-mei & 348.00 & 657.00 \\
\hline Jun-augst & 329.00 & 676.00 \\
\hline Sep-nov & 344.00 & 681.00 \\
\hline
\end{tabular}

Sumber data : Bagian pengadaan bahan baku pada CV. HADI MULYONO AIMAS

2. Biaya setiap kali pemesanan untuk bahan baku fiber cair dan serat fiber sebesar Rp 3.000.000,- dan Rp 1.000.000,-

3. Biaya penyimpanan perbulan untuk bahan baku fiber cair dan serat fiber ditetapkan $9 \%$ dari harganya

4. Harga fiber cair per-kg sebesar Rp 36.500,-

5. Harga serat fiber per-kg sebesar $\mathrm{Rp}$ 38.000,-

6. Lead time selama 3 bulan

\section{PENGOLAHAN DATA}

Adapun pengolahan data setelah data dikumpulkan yaitu :

1. Melakukan proyeksi tingkat kebutuhan bahan baku fiber cair dan serat fiber untuk tahun yang akan dating menggunakan metode konstan, linier, siklik, moving average dan exponensial smoothing.

2. Setelah mengetahui metode peramalan dengan standar deviasi terkecil dan memiliki keseragaman data maka dapat dilanjutkan pada penentuan jumlah produk setiap kali melakukan pemesanan yang ekonomis (EOQ)

3. Penentuan total biaya-biaya yang digunakan selama 5 tahun.

Hasil dari pengolahan data :

Standar deviasi

\begin{tabular}{lcl}
\hline Peramalan & $\begin{array}{c}\text { Fiber } \\
\text { Cair }\end{array}$ & $\begin{array}{c}\text { Serat } \\
\text { Fiber }\end{array}$ \\
\hline Konstan & 21,88 & 10,14 \\
\hline Linier & 22,20 & 10,23 \\
\hline Siklik & 22,38 & 10,52 \\
\hline Moving & 514,72 & 258,83
\end{tabular}




\begin{tabular}{lll}
\hline average & & \\
\hline $\begin{array}{l}\text { Exponensial } \\
\text { smoothing }\end{array}$ & 67,59 & 34,11 \\
\hline
\end{tabular}

Standar deviasi terkecil ada pada peramalan constant.

\section{Untuk bahan baku fiber cair}

1. Permintaan bahan baku fiber cair untuk lima tahun sebanyak $13.478 \mathrm{~kg}$ dan standar deviasi yang paling kecil berada pada peramalan Konstant.

$\mathrm{Sdt}=\sqrt{\frac{\sum\left(d t-d^{\prime} t\right)^{\wedge} 2}{n-1}}=\sqrt{\frac{9093.80}{20-1}}$
$=21,88$

2. Biaya untuk sekali pesan sebesar $\mathrm{Rp}$ 3.000.000,-

3. Harga per-kg bahan baku fiber cair sebesar Rp 36.500,-

4. Biaya penyimpanan bahan baku fiber cair dikenakan 9\% dari harga per-kg yaitu 9\%xRp 36.500,- = Rp 3285,-

Jadi jumlah pesanan bahan baku fiber cair yang optimum untuk sekali pesan adalah

$$
\begin{gathered}
E O Q=\sqrt{\frac{2 D H}{H}} \\
=\sqrt{\frac{2 * 13478 * 3000000}{3285}}=4961,59 \mathrm{~kg}
\end{gathered}
$$

Frekuensi pemesanan dalam 5 tahun

adalah

$\mathrm{t}=\frac{E O Q}{D}=\frac{4961,59}{13478}=0,37$ per -5 tahun

$\mathrm{f}=0,37 \times 1435$ hari $=528,26$ hari

maka $\frac{1435}{528,26}=2,72 \approx 3$ kali pesan per-5 tahun.

Untuk standar deviasi terkecil pada peramalan bahan baku fiber cair yaitu metode peramalan constant adalah $\operatorname{sdt} \sqrt{\frac{\sum\left(d t-d^{\prime} t\right)^{2}}{n-1}}=\sqrt{\frac{9093,80}{20-1}}=21,88$

Sehingga standar deviasi untuk lead time sebesar

$$
\begin{aligned}
& S d t=\sqrt{\frac{L}{30} *(\text { Sdt konstant })^{2}} \\
& S d t=\sqrt{\frac{30}{30} *(21.88)^{2}}=21,88
\end{aligned}
$$

Level of service (a) ditentukan $99 \%$ atau 2,33 (Berdasarkan tabel Policy Factors (K) ) atau frequency level of service.

Maka safety stock atau $\mathrm{B}=\mathrm{axSdt}$ Lead Time $=2,33 \times 21,88$

$$
=50.98 \mathrm{~kg} \approx 51 \mathrm{~kg}
$$

Jadi perbandingan antara system pengendalian persediaan bahan baku fiber cair ini dipergunakan oleh perusahaan dibandingkan dengan menurut metode EOQ ( Economic Order Quantity) adalah sebagai berikut :

1. Menurut Perusahaan

a. Frekuensi pemesanan fiber cair umumnya 8 kali per 5 tahunnya.

b. Rata-rata pesanan tiap kali pesan

$$
\mathrm{Q}=\frac{13478}{8}=1684,75 \mathrm{~kg}
$$

c. Persediaan rata-rata

$$
\mathrm{B}+\frac{Q}{2}=51+\frac{1684,75}{2}=893,38
$$

d. Biaya total persediaan adalah biaya pemesanan ditambah biaya penyimpanan

Biaya pemesanan =

8 x Rp 3,000,000,-x1684,75

$=$ Rp 40,434,000,000,-

Biaya penyimpanan $=3285 \mathrm{x}$

$893,38=\operatorname{Rp~2,934,736.88}$

Jadi total biaya persediaan fiber cair menurut perusahaan adalah

Rp 40,434,000,000,- + Rp 2,934,736.88

$=\operatorname{Rp} 40,436,934,736.88$

2. Menurut EOQ

a. Frekuensi pemesanan fiber cair adalah 3 kali per 5 tahun

b. Rata-rata pesanan setiap kali pesan $\mathrm{Q}=\frac{13478}{3}=4492,67 \mathrm{~kg}$

c. Persediaan rata-rata

$\mathrm{B}+\frac{Q}{2}=51+\frac{4492,67}{2}=2297.34$

d. Total biaya persediaan adalah biaya pemesanan + biaya penyimpanan $=(3 \times 4492,67 \times \operatorname{Rp~3,000,000,~})$ $+(2297.34 \times R p 3285,-)$

$=\mathrm{Rp} 40,434,030,000,-\quad+\mathrm{Rp}$

7,546,745.48

$=\operatorname{Rp} 40,441,576,745.48$

Sedangkan titik pemesanan bahan baku fiber cair kembali (Reorder Point) adalah $\mathrm{ROP}=(\mathrm{UxL})+$ Safety stock.

Dimana $\mathrm{U}=\frac{\text { Kebutuhan }}{3 \text { bulan }}=\frac{13478}{20}$

$=673,9 \mathrm{~kg}$

Sehingga :

$\mathrm{ROP}=(673,9 \mathrm{x} 1)+51=724.9 \approx 725 \mathrm{~kg}$

Jadi pemesanan kembali dapat dilakukan pada saat persediaan bahan baku fiber cair sebanyak $725 \mathrm{~kg}$. 


\section{Untuk bahan baku serat fiber}

1. Permintaan bahan baku serat fiber untuk lima tahun sebanyak $6813 \mathrm{~kg}$ dan untuk standar deviasi yang paling kecil berada pada peramalan constant.

$\mathrm{Sdt}=\sqrt{\frac{\sum\left(d t-d^{\prime} t\right)^{\wedge} 2}{n-1}}=\sqrt{\frac{1952,55}{20-1}}$ $=10,14$

2. Biaya untuk sekali pesan sebesar $\mathrm{Rp}$ $1.000 .000,-$

3. Harga per-kg bahan baku serat fiber sebesar Rp 38.000,-

4. Biaya penyimpanan bahan baku serat fiber dikenakan 9\% dari harga per-kg yaitu 9\%xRp 38.000,- = Rp 3420,-

Jadi jumlah pesanan bahan baku serat fiber yang optimum untuk sekali pesan adalah

$E O Q=\sqrt{\frac{2 D S}{H}}=\sqrt{\frac{2 * 6813 * 1000000}{3420}}$

$=1996,05 \mathrm{~kg}$

adalah

Frekuensi pemesanan dalam 5 tahun

$\mathrm{t}=\frac{E O Q}{D}=\frac{1996,05}{6813}=0,29$ per -5 tahun

$\mathrm{f}=0,29 \times 1435$ hari $=420,42$ hari

maka $\frac{1435}{420,42}=3,41 \approx 3$ kali pesan per-5 tahun.

Untuk standar deviasi terkecil pada peramalan bahan baku serat fiber yaitu metode peramalan constant adalah $\operatorname{sdt} \sqrt{\frac{\sum\left(d t-d^{\prime} t\right)^{2}}{n-1}}=\sqrt{\frac{1952,55}{20-1}}=10,14$

Sehingga standar deviasi untuk lead time sebesar

$$
\begin{aligned}
& S d t=\sqrt{\frac{L}{30} *(\text { Sdt konstant })^{2}} \\
& S d t=\sqrt{\frac{30}{30} *(10,14)^{2}}=10,14
\end{aligned}
$$

Level of service (a) ditentukan $99 \%$ atau 2,33 (Berdasarkan tabel Policy Factors (K)) atau frequency level of service.

Maka safety stock atau B $=$ axSdt

Lead Time $=2,33 \times 10,14$

$$
=23,62 \mathrm{~kg} \approx 24 \mathrm{~kg}
$$

Jadi perbandingan antara system pengendalian persediaan bahan baku serat fiber ini dipergunakan oleh perusahaan dibandingkan dengan menurut metode EOQ ( Economic Order Quantity ) adalah sebagai berikut :
1. Menurut Perusahaan

a. Frekuensi pemesanan serat fiber umumnya 8 kali per 5 tahunnya.

b. Rata-rata pesanan tiap kali pesan $\mathrm{Q}=\frac{6813}{8}=851.63 \mathrm{~kg}$

c. Persediaan rata-rata

$\mathrm{B}+\frac{Q}{2}=24+\frac{851.63}{2}=449.81$

d. Biaya total persediaan adalah biaya pemesanan ditambah biaya penyimpanan

Biaya pemesanan $=8 \times \operatorname{Rp~1,000,000,-x851.63}$

$=\operatorname{Rp~6,813,000,000,-}$

Biaya penyimpanan

$=449.81 \times 3420$

$=\operatorname{Rp} 1,538,358.75$

Jadi total biaya persediaan serat fiber menurut perusahaan adalah $\mathrm{Rp}$ $6,813,000,000,-+\operatorname{Rp} 1,538,358.75=\mathrm{Rp}$ $6,814,538,358.75$

2. Menurut EOQ

a. Frekuensi pemesanan serat fiber adalah 3 kali per 5 tahun

b. Rata-rata pesanan setiap kali pesan $\mathrm{Q}=\frac{6813}{3}=2271 \mathrm{~kg}$

c. Persediaan rata-rata $\mathrm{B}+\frac{Q}{2}=24+\frac{2271}{2}=1159.5$

d. Total biaya persediaan adalah biaya pemesanan + biaya penyimpanan $=(3 \times 2271 \times \mathrm{Rp} 1,000,000,-)+$ (1159.5 xRp 3420,-) $=\operatorname{Rp~6,816,965,490,-}$

Sedangkan titik pemesanan bahan baku serat fiber kembali (Reorder Point) adalah $\mathrm{ROP}=(\mathrm{UxL})+$ Safety stock.

Dimana $\mathrm{U}=\frac{\text { Kebutuhan }}{3 \text { bulan }}=\frac{6813}{20}=340.65 \approx$ $341 \mathrm{~kg}$

Sehingga :

$\mathrm{ROP}=(341 \mathrm{x} 1)+24=365 \mathrm{~kg}$

Jadi pemesanan kembali dapat dilakukan pada saat persediaan bahan baku serat fiber sebanyak $365 \mathrm{~kg}$.

\section{P E N U T U P \\ Kesimpulan}

Bahan baku fiber cair :

1. Metode Peramalan Konstant yang tepat digunakan karena memiliki standar deviasi data yang terkecil sebesar 21,88. 
2. Jumlah pemesanan bahan baku Fiber Cair yang optimum sebesar $13.478 \mathrm{~kg}$.

3. Frekuensi pemesanan bahan baku Fiber Cair adalah 3 kali per 5 tahun. Sedangkan menurut perusahaan 8 kali per 5 tahun.

4. Rata-rata pesanan setiap kali pesan $4.492,67 \mathrm{~kg}$ dengan persediaan rata-rata 2.297,34 kg dengan total biaya persediaan sebesar Rp 40.441.576.745,48. Sedangkan menurut perusahaan sebesar $\quad \mathrm{Rp}$ 40,436,934,736.88.

5. Reorder Point bahan baku Fiber Cair pada saat persediaan bahan baku Fiber Cair sebesar $725 \mathrm{~kg}$.

\section{Bahan baku fiber serat}

1. Metode Peramalan Konstan yang tepat digunakan karena memiliki standar deviasi data yang terkecil sebesar 10,14.

2. Jumlah pemesanan Bahan Baku Serat Fiber yang optimum sebesar $6.813 \mathrm{~kg}$.

3. Frekuensi pemesanan Bahan Baku Serat Fiber adalah 3 kali per 5 tahun. Sedangkan menurut perusahaan 8 kali per 5 tahun.

4. Rata-rata pesanan setiap kali pesan 2.271 $\mathrm{kg}$ dengan persediaan rata-rata $1.159,5 \mathrm{~kg}$ dengan total biaya persediaan sebesar $\mathrm{Rp}$ 6.816.965.490,-. Sedangkan menurut perusahaan sebesar Rp 6,814,538,358.75.

5. Reorder Point bahan baku Serat Fiber pada saat persediaan bahan baku Serat Fiber sebesar $365 \mathrm{~kg}$.

\section{Saran}

1. Evaluasi terhadap metode yang digunakan yang sesuai dengan permintaan pelanggan.

2. Menentukan planning material dan in material karena ini langkah untuk melakukan operasional yang efisien.

3. Perlu adanya sumberdaya manusia yang berkompetisi dalam hal analisis atau yang menguasai akuntansi biaya untuk perusahaan industtri.

4. Letak perusahaan kurang strategis karena berada pada daerah pemukiman warga yang padat, sehingga perlu adanya tata ruang khusus untuk perusahaan industry.
5. Perbedaan analisis antara perusahaan dengan menurut metode EOQ disebabkan karena frekuensi pemesanan.

6. Diharapkan perusahaan lebih memperhatikan tentang minat pelanggan dengan menggunakan strategi marketing mix diantaranya menyangkut produk, place dan price.

\section{DAFTAR PUSTAKA}

Agung I, Khaist, 2010. Laporan pengendalian Persediaan.

Rangkuti, Freddy, 1996. Managemen Persediaan(Aplikasi dibBidang Bisnis). Penerbit : PT. RajaGrafindo Persada, Jakarta

Yamit, Zulian. 2005. Managemen Persediaan(cetakan Ketiga). Penerbit : Ekonisia Fakultas Ekonomi UII Yogyakarta, Yogyakarta 